\title{
Amphetamine Paradoxically Augments Exocytotic Dopamine Release and Phasic Dopamine Signals
}

\author{
D.P. Daberkow, ${ }^{1 \star}$ H.D. Brown, ${ }^{2 \star}$ K.D. Bunner, ${ }^{1}$ S.A. Kraniotis, ${ }^{1}$ M.A. Doellman, ${ }^{1}$ M.E. Ragozzino, ${ }^{2}$ P.A. Garris, ${ }^{1}$ \\ and M.F. Roitman ${ }^{2}$ \\ ${ }^{1}$ School of Biological Sciences, Cell Biology, Physiology and Development Section, Illinois State University, Normal, Illinois 61790, and ${ }^{2}$ Department of \\ Psychology, University of Illinois at Chicago, Chicago, Illinois 60607
}

\begin{abstract}
Drugs of abuse hijack brain-reward circuitry during the addiction process by augmenting action potential-dependent phasic dopamine release events associated with learning and goal-directed behavior. One prominent exception to this notion would appear to be amphetamine (AMPH) and related analogs, which are proposed instead to disrupt normal patterns of dopamine neurotransmission by depleting vesicular stores and promoting nonexocytotic dopamine efflux via reverse transport. This mechanism of AMPH action, though, is inconsistent with its therapeutic effects and addictive properties, which are thought to be reliant on phasic dopamine signaling. Here we used fast-scan cyclic voltammetry in freely moving rats to interrogate principal neurochemical responses to AMPH in the striatum and relate these changes to behavior. First, we showed that AMPH dose-dependently enhanced evoked dopamine responses to phasic-like current pulse trains for up to $2 \mathrm{~h}$. Modeling the data revealed that AMPH inhibited dopamine uptake but also unexpectedly potentiated vesicular dopamine release. Second, we found that AMPH increased the amplitude, duration, and frequency of spontaneous dopamine transients, the naturally occurring, nonelectrically evoked, phasic increases in extracellular dopamine. Finally, using an operant sugar reward paradigm, we showed that low-dose AMPH augmented dopamine transients elicited by sugar-predictive cues. However, operant behavior failed at high-dose AMPH, which was due to phasic dopamine hyperactivity and the decoupling of dopamine transients from the reward predictive cue. These findings identify upregulation of exocytotic dopamine release as a key AMPH action in behaving animals and support a unified mechanism of abused drugs to activate phasic dopamine signaling.
\end{abstract}

\section{Introduction}

All abused drugs share midbrain dopamine neurons as a common ultimate target. Although specific mechanisms vary and include direct, indirect, and multiple actions, the overall outcome is a hyperdopamine state (Lüscher and Ungless, 2006; Willuhn et al., 2010). For a broad class of abused drugs, psychostimulants and otherwise, including cocaine, nicotine, and ethanol, dopamine activation is manifested in enhanced phasic release events (Cheer et al., 2007). These transient increases in extracellular dopamine are generated by brief bursts of action potentials (Schultz, 2007; Sombers et al., 2009), occur spontaneously, and are also time-locked to unexpected affective stimuli or their predictors (Day et al., 2007; Roitman et al., 2008). Phasic dopamine signaling is critical to the formation and expression of associa-

\footnotetext{
Received May 3, 2012; revised 0ct. 29, 2012; accepted Nov. 8, 2012.

Author contributions: D.P.D., H.D.B., M.E.R., P.A.G., and M.F.R. designed research; D.P.D., H.D.B., K.D.B., S.A.K., and M.A.D. performed research; D.P.D., H.D.B., P.A.G., and M.F.R. analyzed data; D.P.D., H.D.B., M.E.R., P.A.G., and M.F.R. wrote the paper.

This work was supported by the National Institute on Drug Abuse (Grants DA021770 and DA024036 to P.A.G. and DA025634 to M.F.R.), the National Institute of Child Health and Human Development (Grant HD055751 to M.E.R.), the National Science Foundation (Grant DBI0754615 to P.A.G.) and Illinois State University (grants to P.A.G.).

${ }^{*}$ D.P.D. and H.D.B. contributed equally to this work.

Correspondence should be addressed to either Dr. Mitchell F. Roitman, 1007 W. Harrison St., MC285, Chicago, IL 60607, E-mail: mroitman@uic.edu; or Dr. Paul A. Garris, School of Biological Sciences, 210 Julian Hall, Illinois State University, Normal, IL 61790-4120, E-mail: pagarri@ilstu.edu.

D.P. Daberkow's present address: Biology Department, Eastern Washington University.

DOI:10.1523/JNEUROSCI.2136-12.2013

Copyright $\odot 2013$ the authors $\quad 0270-6474 / 13 / 330452-12 \$ 15.00 / 0$
}

tions underlying learning and goal-directed behavior (Tsai et al., 2009; Zweifel et al., 2009). Most importantly, augmentation above that elicited by natural rewards is proposed to cause overlearning of cues predicting drug availability and underlie a "pathological usurpation" of reward-related learning mechanisms during addiction (Hyman et al., 2006).

While it is attractive to postulate that all abused drugs enhance phasic dopamine signaling, amphetamine (AMPH) and its analogs present a major challenge to this unifying hypothesis. AMPH exhibits several well documented effects on dopamine neurotransmission, including increasing synthesis and inhibiting degradation and uptake, but its ability to cause efflux as a "releaser" is considered the sine qua non mechanism (Fleckenstein et al., 2007; Sulzer, 2011). This nonexocytotic type of dopamine release is mediated by AMPH reversing dopamine transporter (DAT) direction, and is enhanced by AMPH redistributing dopamine from vesicular to cytosolic pools. The implication, which has been empirically demonstrated in vitro, is that AMPH compromises exocytotic dopamine release and floods the extracellular space with micromolar dopamine (Jones et al., 1998; Schmitz et al., 2001) sufficient to saturate both low-affinity and highaffinity dopamine receptors (Richfield et al., 1989). Under such conditions, the ability of phasic dopamine signaling to respond dynamically to rewards and their predictive cues should be entirely eliminated.

AMPH and its analogs improve learning and goal-directed behavior (Wyvell and Berridge, 2000; Knutson et al., 2004). Thus, 
there appears to be a discrepancy regarding the mechanism of $\mathrm{AMPH}$ action that is perhaps preparation based, with $\mathrm{AMPH}$ disrupting normal modes of dopamine neurotransmission in vitro yet, at the whole organism level, improving behavioral processes dependent on phasic dopamine signaling. Recent work in anesthetized rats demonstrating that AMPH enhances electrically evoked phasic-like dopamine responses with minimal activation of the nonexocytotic dopamine efflux (Ramsson et al., 2011a,b) provides insight into in vivo AMPH action, but these measurements may be distorted by anesthesia. Here we address this discrepancy using real-time microsensors in freely moving rats. This approach not only affords assessment of AMPH effects on behaviorally associated phasic dopamine signals (Brown et al., 2011), but also of the key AMPH cellular targets-exocytotic dopamine release and DAT - in the intact brain of an ambulatory animal and in the absence of anesthesia artifacts (Garris et al., 2003). Together, our results support reassessing AMPH mechanism of action.

\section{Materials and Methods}

Drugs. D-Amphetamine (Sigma-Aldrich) was dissolved in sterile saline $(0.9 \%)$ and injected intraperitoneally.

Animals. Adult, male Sprague Dawley rats (300-400 g) were housed individually in a temperature-controlled room maintained on a $12 \mathrm{~h}$ light/dark cycle and allowed access to food and water ad libitum except when indicated below. Animal care and experimental procedures conformed to the National Institutes of Health Guide for the Care and Use of Laboratory Animals and were approved by the Institutional Animal Use and Care Committees at Illinois State University and the University of Illinois at Chicago.

Carbon-fiber microelectrodes. Individual carbon fibers $(r=3.5 \mu \mathrm{m}$, Cytec Engineering Materials) were pulled and sealed (Narishige micropipette puller) in glass capillary tubes (Sutter Instruments). To create a cylinder carbon-fiber microelectrode (CFM), the exposed end of the fiber was cut $100-200 \mu \mathrm{m}$ distal to the glass-insulating seal.

Surgery. As previously described (Garris et al., 2003; Ebner et al., 2010), rats were affixed with headmounts suitable for stimulating and recording dopamine while freely moving. In brief, rats were anesthetized with ketamine $(80 \mathrm{mg} / \mathrm{kg})$ and xylazine $(60 \mathrm{mg} / \mathrm{kg})$, injected intraperitoneally, and immobilized in a stereotaxic frame. Stereotaxic coordinates were obtained from the atlas of Paxinos and Watson (1986). After holes were drilled through the skull, an electrode guide for CFM positioning was placed over the dorsomedial striatum $[+1.2$ anteroposterior (AP), + 1.5 mediolateral (ML), -4.5 dorsoventral (DV)], and a chlorinated silver wire reference electrode was lowered in the contralateral cortex. A twisted bipolar stimulating electrode (Plastics One) with $\sim 1 \mathrm{~mm}$ tip separation was incrementally lowered to the medial forebrain bundle $(-4.6 \mathrm{AP},+1.4 \mathrm{ML},-7.5 \mathrm{DV})$ or ventral tegmental area/substantia nigra region $(-5.2 \mathrm{AP},+0.8 \mathrm{ML},-8.4 \mathrm{DV})$. Constant current, biphasic stimulus pulses $(60 \mathrm{~Hz}, 24$ pulses, $125 \mu \mathrm{A})$ were applied (NL 800, Neurolog, Medical Systems) until a robust dopamine signal was evoked. The CFM was removed, and the electrode guide, stimulating electrodes, and reference electrodes were cemented to the skull with the aid of surgical screws.

Electrochemistry. Dopamine measurements were recorded with fastscan cyclic voltammetry by applying a triangular waveform $(-0.4-1.3 \mathrm{~V}$ and back, $400 \mathrm{~V} / \mathrm{s}$ ) every $100 \mathrm{~ms}$ to the CFM. Both the headstage and potentiostat were custom-made (University of North Carolina at Chapel Hill, Department of Chemistry Instrument Shop; or Department of Psychiatry and Behavioral Sciences, University of Washington). Cyclic voltammograms were background-subtracted using baseline scans averaged before stimulation, drug-evoked events, or time-stamps related to behavior. Time-dependent signals were obtained by monitoring current around the peak oxidative potential for dopamine $(\sim+600 \mathrm{mV})$. After the recording session, the CFM was postcalibrated with flow-injection analysis (Logman et al., 2000; Sinkala et al., 2012). For recordings made during the discriminative stimulus paradigm, principal component re- gression of the data was performed to obtain time-dependent changes in dopamine concentration as previously described (Day et al., 2007; Brown et al., 2011).

Measurements with electrical stimulation. Recording of electrically evoked dopamine signals occurred 3-7 d after surgery. Rats were habituated to a walled-off, open-field chamber $(16 \times 16$ inches; 8.5 inch walls $)$ for 15-30 min. A headstage and stimulating electrode connector cable were attached to the rats at one end and a commutator at the other. After attaching a micromanipulator, a fresh CFM was incrementally lowered into the dorsomedial striatum until a robust electrically evoked dopamine signal was recorded. Once optimized, the position of the CFM was secured with the micromanipulator lock. Evoked dopamine signals were elicited and recorded every $5 \mathrm{~min}$ for $15 \mathrm{~min}$ during the predrug session. Saline or AMPH was injected, and dopamine signals were evoked and recorded every $5 \mathrm{~min}$ for $2 \mathrm{~h}$ during the postdrug session (saline, $n=5 ; 1$ $\mathrm{mg} / \mathrm{kg}$ AMPH, $n=5 ; 10 \mathrm{mg} / \mathrm{kg}$ AMPH, $n=6$ ). Changes in the measured current at the peak oxidative potential for dopamine were analyzed in between applications of stimulus trains and used as an index of dopamine efflux. In addition, spontaneous dopamine transients were also continuously monitored throughout predrug and postdrug sessions. AMPH-induced changes in motoric behavior were coded from video recordings. Ambulatory activity was defined and quantified as the number of quadrant line crossings. The open field was divided into four quadrants and if half or more of a rat's body crossed a quadrant line, it was considered a crossing. Stereotypy was defined and quantified as any repetitive movement for longer than $1 \mathrm{~s}$.

Discriminative stimulus paradigm. Rats were trained and tested in a standard operant chamber (Med Associates). A houselight and two different sound generators were located on one wall of the chamber. A custom-designed acrylic pellet receptacle was located in the center of the opposite wall. Retractable levers with a circular white cue light above them were positioned on either side of and equidistant to the pellet receptacle. A hole in the top of the chamber allowed for the attachment of the headstage for voltammetric measurements. The headstage, in turn, was attached to a commutator mounted above to allow for free movement of the subject.

Rats were trained on a discriminative stimulus paradigm as previously described (Jones et al., 2010). Rats $(n=20)$ were initially food-restricted ( $\sim 95 \%$ pretraining body weight) and trained to press levers for a sugar pellet reward. Depression of either lever resulted in both levers immediately retracting and a sugar pellet being delivered into the food receptacle. After $5 \mathrm{~s}$, the levers were extended into the chamber again. Rats received daily 30 min sessions until 50 lever presses were made on either of the levers for at least 2 consecutive days. On the following day, the discriminative stimulus paradigm began. In this task, a discrete audiovisual cue was presented $3 \mathrm{~s}$ before extension of one lever. A different audiovisual cue was presented $3 \mathrm{~s}$ before extension of the other lever. Presentation of one set of cues (DS+) followed by a response on the associated lever resulted in the delivery of a sugar pellet. Presentation of the other set of cues (DS-) followed by a response on the associated lever resulted in no programmed response. Levers were retracted immediately after a response or after $5 \mathrm{~s}$ if no response was made. Thus, the end of each trial was marked by either pellet delivery (correct DS + response) or lever retraction (incorrect DS - response or after $5 \mathrm{~s}$ with no response on either DS+ or DS - trials). Audiovisual stimuli and rewarded versus nonrewarded levers were counterbalanced across rats. Each training session consisted of 60 trials (30 DS +, $30 \mathrm{DS}-$ ) that were presented pseudorandomly with a randomly selected intertrial interval (11-19 s; mean, $15 \mathrm{~s})$. Once rats responded on $90 \%$ DS + trials and abstained on $70 \%$ of DS - trials for 2 consecutive days, they were prepared for voltammetric recordings. Following recovery from surgery, rats were again food-restricted and retrained to criteria. During postoperative training, rats were connected to a headstage to acclimate to voltammetric recording procedures. Once rats reached task criteria, testing began the following day. On the test day, a CFM was lowered into the dorsomedial striatum and voltammetric measurements were made during the discriminative stimulus paradigm. After 24 (12 DS +, 12 DS -) trials (predrug), the session was paused and each rat received an intraperitoneal injection of saline $(n=7), 1 \mathrm{mg} / \mathrm{kg}$ AMPH $(n=6)$, or $5 \mathrm{mg} / \mathrm{kg}(n=7) \mathrm{AMPH}$. After $10 \mathrm{~min}$ postinjection, 
the session resumed and recordings were made for an additional 40 trials (20 DS+, 20 DS-).

Analysis of exocytotic dopamine release and neuronal dopamine uptake. Voltammetric dopamine signals resulting from delivery of current pulse trains were analyzed using a kinetic model describing evoked levels as a balance between dopamine release and uptake mechanisms (Wu et al., 2001), as shown in Equation 1: $d[\mathrm{DA}] / d t=[\mathrm{DA}]_{\mathrm{p}}{ }^{*} f-k[\mathrm{DA}]$, where $f$ is the frequency of stimulation. In the model, both dopamine release and uptake operate during the stimulation train, but only dopamine uptake operates after cessation of the stimulus to return evoked dopamine levels to baseline. Curve fitting of data to Equation 1 used a simplex minimization algorithm to obtain the exocytotic dopamine release term, $[\mathrm{DA}]_{\mathrm{p}}$, and $k$, the first-order rate constant, for neuronal dopamine uptake $(\mathrm{Wu}$ et al., 2001).

Two additional analyses were used to determine $[D A]_{p}$. The first, single-curve analysis, is based on the assumption that the rising phase of the evoked dopamine signal is dependent on the balance between release and uptake, while the falling phase is solely dependent on uptake (Wu et al., 2001). As such, an algebraic subtraction of the falling phase slope (uptake) from the rising phase slope (release and uptake) resolves the dopamine release term, $[\mathrm{DA}]_{\mathrm{p}}$. The only assumption regarding uptake in this analysis is that the rate of uptake is identical for the rising and falling phases at the same concentration. The second analysis assumes that dopamine uptake follows Michaelis-Menten kinetics (Wu et al., 2001). Thus, evoked dopamine dynamics were fit to Equation 2: $d[\mathrm{DA}] / d t=$ $[\mathrm{DA}]_{\mathrm{p}}{ }^{*} f-V_{\max } /\left(K_{\mathrm{m}} /[\mathrm{DA}]+1\right)$, where $K_{\mathrm{m}}$ is inversely related to the affinity of dopamine for the transporter and $V_{\max }$ is the maximal velocity of dopamine uptake. Assuming that $V_{\max }$ does not change at early time points after AMPH administration (i.e., competitive inhibition), $V_{\max }$ was determined from the predrug response and fixed during analysis of the postdrug response recorded at $10 \mathrm{~min}$ postdrug to determine $[\mathrm{DA}]_{\mathrm{p}}$ and $K_{\mathrm{m}}$ (Garris et al., 2003). $K_{\mathrm{m}}$ was assumed to be $0.2 \mu \mathrm{M}$ for the predrug analysis (Wu et al., 2001).

Dopamine transients. Spontaneous dopamine transients monitored before and after AMPH were identified based on the characteristic shape of each cyclic voltammogram recorded every $100 \mathrm{~ms}$ in a $5 \mathrm{~min}$ data file. Cyclic voltammograms were first background-subtracted from the previous 10 cyclic voltammograms. A background-subtracted cyclic voltammogram from the maximal electrically evoked dopamine response recorded at the beginning of each file was used as a template to identify dopamine cyclic voltammograms in the entire $5 \mathrm{~min}$ data file. Each cyclic voltammogram was compared with the template-evoked dopamine cyclic voltammogram via TH-1 software (ESA) with the correlation coefficient set at $\geq 0.75$. Current deflection events were only identified as dopamine transients if cyclic voltammograms matched the evoked dopamine cyclic voltammogram template for two consecutive scans (Cheer et al., 2004).

Statistical analysis. For measurements with electrical stimulation, most statistical analyses were performed using SAS version 9.1 (SAS Institute). Time courses for $[\mathrm{DA}]_{\max },[\mathrm{DA}]_{\mathrm{p}}$, and $k$ were compared using a repeated-measures ANOVA with orthogonal contrasts. AMPH-induced changes in basal dopamine levels, and single-curve and Michaelis-Menten analyses were compared using a one-way ANOVA followed by comparisons using Bonferroni post hoc analysis. AMPH-induced increases in dopamine transient duration and amplitude were compared with a $t$ test. Correlation analyses were based on a linear regression model (Systat Software). All correlations were based on the averaged data described in Figure 2, and all 12 points in the time course were used. Thus, all animals analyzed in Figure 2 were used for correlations, and $n$ is related to number of time points in the correlation. For example, when both drug doses are combined in a correlation, $n=24$, whereas when drug doses are correlated individually, $n=12$. For discriminative stimulus paradigm, statistical comparisons were made using Prism (Graphpad). The frequency of dopamine transients was compared using a one-way ANOVA and the post hoc Tukey's test. The time courses of dopamine concentration within the discriminative stimulus paradigm were compared using a two-way ANOVA followed by Tukey's test. In all cases, statistical significance was set at $p \leq 0.05$.

\section{Results}

AMPH increases electrically evoked phasic-like dopamine signals

Using fast-scan cyclic voltammetry at a CFM, we measured dopamine with $100 \mathrm{~ms}$ time resolution in the dorsal striatum of freely moving rats. In addition to fine temporal and spatial resolution for in situ neurotransmitter monitoring, this technique provides a chemical signature in the form of a voltammogram to identify the analyte (Heien et al., 2004). Pulse trains, for which rats will self-administer (Cheer et al., 2005), were delivered to ascending dopamine fibers. This reinforcing electrical stimulation evoked phasic-like dopamine release events that were enhanced in amplitude and duration by AMPH (Fig. 1A; AMPH was injected i.p. for all measurements in the present study). Background-subtracted voltammograms identified the released chemical species as dopamine (Fig. $1 \mathrm{~A}$, inset; Fig. $1 \mathrm{~B}$ ). Indeed, both 1 and $10 \mathrm{mg} / \mathrm{kg}$ AMPH potentiated the maximal concentration of electrically evoked dopamine $\left([\mathrm{DA}]_{\max }\right)$ compared with saline control for almost $2 \mathrm{~h}$ (Fig. 2A). Indicating dosedependent drug effects, the onset of phasic-like dopamine activation following $10 \mathrm{mg} / \mathrm{kg}$ AMPH was more rapid, with the increase following $1 \mathrm{mg} / \mathrm{kg}$ AMPH more sustained. Statistical analysis of $[\mathrm{DA}]_{\max }$ revealed an overall significant effect of treatment $\left(F_{(2,12)}=13.6, p<0.01\right)$ and time $(p<0.05)$, with both doses significantly different from saline $(1 \mathrm{mg} / \mathrm{kg}, p<0.05 ; 10$ $\mathrm{mg} / \mathrm{kg}, p<0.01)$ and $1 \mathrm{mg} / \mathrm{kg}$ significantly different from 10 $\mathrm{mg} / \mathrm{kg}(p<0.05)$. Rather than interfere with action potentialdependent dopamine neurotransmission as previously proposed (Fleckenstein et al., 2007; Sulzer, 2011), these results alternatively indicate that AMPH augments electrically evoked phasic-like dopamine signals acutely in the awake animal for what behaviorally are considered a low $(1 \mathrm{mg} / \mathrm{kg})$ and high $(10 \mathrm{mg} / \mathrm{kg})$ dose that elicits ambulation and stereotypy, respectively (Fig. 2B) (Kuczenski et al., 1991).

\section{AMPH increases exocytotic dopamine release and decreases dopamine uptake}

Because both exocytotic dopamine release and neuronal dopamine uptake mechanisms operate during the rewarding pulsetrain stimulation and contribute to the amplitude of the electrically evoked signal recorded in vivo (Wu et al., 2001), observed AMPH-induced increases in $[\mathrm{DA}]_{\max }$ could be due to DAT inhibition. Reducing the rate of dopamine uptake is another hallmark action of AMPH on dopamine neurotransmission established by in vitro studies (Fleckenstein et al., 2007; Sulzer, 2011) and is suggested here by the slowed extracellular clearance of dopamine after stimulation (Fig. 1). Thus, because pulse trains were used, DAT inhibition could mask the expected decrease in exocytotic dopamine release due to depleted vesicular stores. To test this possibility, evoked responses were fit to a kinetic model mathematically resolving dopamine release and uptake components based on their distinct time dependences (Eq.1) (Wu et al., 2001). Consistent with established pharmacology, AMPH inhibited dopamine uptake when analyzed as a first-order rate constant $(k)$ in a dose-dependent fashion (Fig. 2C). While $1 \mathrm{mg} / \mathrm{kg}$ AMPH elicited a more transient inhibition of dopamine uptake that peaked $\sim 25 \mathrm{~min}$ postinjection, a dose of $10 \mathrm{mg} / \mathrm{kg}$ sustained an $80 \%$ reduction for the entire $2 \mathrm{~h}$ time course. Statistical analysis of $k$ revealed an overall significant effect of treatment $\left(F_{(2,11)}=\right.$ 26.7, $p<0.0001)$ but not time $(p=0.12)$. Both doses were significantly different from saline $(1 \mathrm{mg} / \mathrm{kg}, p<0.01 ; 10 \mathrm{mg} / \mathrm{kg}$, $p<0.01$ ), and $1 \mathrm{mg} / \mathrm{kg}$ was significantly different from $10 \mathrm{mg} / \mathrm{kg}$ $(p<0.005)$. Unexpectedly and in sharp contrast to the pro- 
A



B
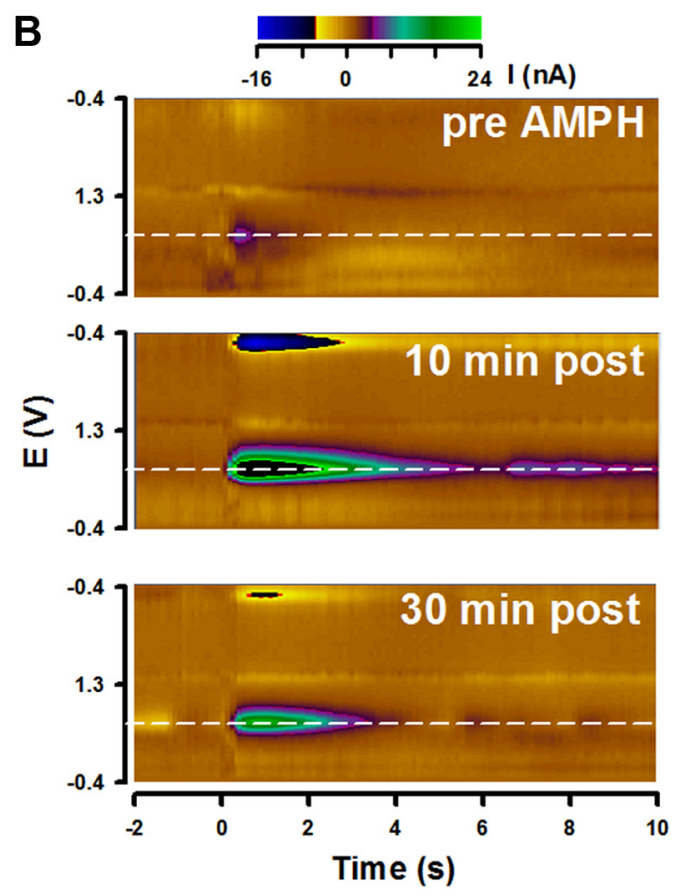

Figure 1. AMPH augments action potential-dependent dopamine neurotransmission in awake rats. Dopamine signals in the dorsomedial striatum were evoked by electrical stimulation of ascending dopamine fibers $(60 \mathrm{~Hz}, 24$ pulses, $125 \mu \mathrm{A})$. A, Data show pre-AMPH injection (solid line) and effects of AMPH (10 mg/kg) on the evoked dopamine signal $10 \mathrm{~min}$ postinjection (dotted line) and 30 min postinjection (dashed line). Inset, Individual background-subtracted cyclic voltammograms identify dopamine (scale bar, I = $3.0 \mathrm{nA}$ ). $\boldsymbol{B}$, Pseudo-color plots ( $x$-axis, time; $y$-axis, applied potential; $z$-axis, measured current) show the entire electrochemical profile supporting the identification of dopamine as the origin of the evoked responses.

nounced decreases reported in vitro, we found that AMPH also elicited a robust, dose-dependent increase in $[\mathrm{DA}]_{\mathrm{p}}$, the parameter for exocytotic dopamine release (Fig. 2D). With a time course similar to $[\mathrm{DA}]_{\max }$, the effects of AMPH on evoked dopamine release were both immediate, as they were increased within $5 \mathrm{~min}$, and prolonged, as they were maintained for nearly the entire $2 \mathrm{~h}$ recording period. Statistical analysis of $[\mathrm{DA}]_{\mathrm{p}}$ revealed an overall significant effect of treatment $\left(F_{(2,11)}=6.53, p<0.05\right)$ and time $(p<0.05)$. The $10 \mathrm{mg} / \mathrm{kg}$ dose was significantly different from saline $(p<0.01)$. A trend toward a significant difference was observed between $1 \mathrm{mg} / \mathrm{kg}$ AMPH and saline $(p=0.059)$.

Additional analyses were performed to verify the surprising result of an AMPH-induced activation of exocytotic dopamine release. A sole alteration in either exocytotic dopamine release or neuronal dopamine uptake was not sufficient to fully capture the AMPH effects on evoked phasic-like dopamine signals (Fig. $3 A$ ). This result was demonstrated by fixing one parameter at the predrug value and then exclusively altering the other in an attempt to mimic the measured AMPH response. Neither a calculated increase in dopamine release nor a calculated decrease in dopamine uptake alone well describes the observed AMPH-induced change in evoked dopamine dynamics. The suitability of using firstorder uptake kinetics, which was initially selected to simplify the measurement of dopamine uptake, was also assessed. First, $[\mathrm{DA}]_{\mathrm{p}}$ was calculated without assuming a kinetic mechanism for neuronal dopamine uptake. This procedure, called single-curve analysis, also demonstrated a dose-dependent, upregulation of exocytotic dopamine release for the $10 \mathrm{~min}$ post-AMPH responses (Fig. $3 B$ ). Statistical analysis of $[\mathrm{DA}]_{\mathrm{p}}$ calculated with single-curve analysis demonstrated an overall significant effect of treatment $\left(F_{(2,13)}=\right.$ 46.6, $p<0.01)$ and significant differences between 1 and 10 $\mathrm{mg} / \mathrm{kg}$ doses and saline $(p<0.05)$ and between AMPH doses $(p<0.05)$. Second, inhibition of dopamine uptake was characterized using Michaelis-Menten kinetics (Eq. 2). Analyzing the same 10 min postdrug responses and assuming competitive inhibition revealed that AMPH elicited a dose-dependent increase in $K_{\mathrm{m}}$ (Fig. 3C). This result is consistent with uptake inhibition as reflected by a decrease in the first-order rate constant (Fig. 2C). Statistical analysis of $K_{\mathrm{m}}$ showed an overall significant effect of treatment $\left(F_{(2,13)}=10.4, p<0.01\right)$ and significant differences between both doses and saline $(p<0.05)$ and between AMPH doses $(p<0.05)$. Along with competitive uptake inhibition, AMPH concurrently elicited a dose-dependent increase in exocytotic dopamine release with AMPH (Fig. 3D). Statistical analysis of $[D A]_{p}$ determined with Michaelis-Menten kinetics showed an overall significant effect of treatment $\left(F_{(2,13)}=24.9, p<0.01\right)$ and significant differences between both doses and saline $(p<$ $0.05)$ and between AMPH doses $(p<0.05)$. Further solidifying this novel mechanism of AMPH action, both alternative strategies for determining exocytotic dopamine release (Fig. $3 B, D$ ) showed quantitatively similar increases as the original analysis (Fig. 2D), and simulated curves calculated using first-order and Michaelis-Menten uptake kinetics coupled with an augmented dopamine release term agree favorably with data (Fig. 3D, inset).

\section{AMPH-induced changes in dopamine neurotransmission and} behavior are correlated

We propose that a concomitant increase in exocytotic dopamine release and decrease in dopamine uptake underlie the observed effects of low and high doses of AMPH on $[\mathrm{DA}]_{\max }$ evoked by electrically stimulating dopamine fibers with phasic-like pulse trains. However, inspection of Figure 1 suggests that augmented dopamine release (Fig. 1D) tracks evoked [DA $]_{\max }$ (Fig. 1A) more faithfully than decreased dopamine uptake (Fig. $1 C$ ). To further understand the respective contributions of these parameters to the regulation of AMPH-induced changes in extracellular dopamine and behavior, we performed correlation analysis. Overall, $[\mathrm{DA}]_{\max }$ was better correlated with exocytotic dopamine 
release than neuronal dopamine uptake $\left(r^{2}=0.977, p<0.01\right.$ and $r^{2}=0.372, p<$ 0.01 , respectively), highlighting the importance of exocytotic dopamine release in establishing the amplitude of phasic dopamine signals after AMPH administration. Upregulated dopamine release was also the better predictor of ambulatory behavior for both low $\left(r^{2}=0.846\right.$; $p<0.01)$ and high $\left(r^{2}=0.699 ; p<0.01\right)$ doses of AMPH than inhibited dopamine uptake $\left(r^{2}=0.719, p<0.01\right.$ and $r^{2}=$ 0.077, $p=0.39$, respectively), but was poorly correlated with stereotypy $\left(r^{2}=\right.$ 0.009 for $10 \mathrm{mg} / \mathrm{kg}$ dose; $p=0.77$ ). In contrast, a highly significant correlation was found for dopamine uptake inhibition and stereotypy $\left(r^{2}=0.725\right.$ for 10 $\mathrm{mg} / \mathrm{kg}$ dose; $p<0.01)$. Together, these results support AMPH-induced increases in exocytotic dopamine release as a key determinant of phasic dopamine signaling in vivo and suggest that the presynaptic mechanisms of dopamine release and uptake may differentially contribute to the dose-dependent motoric responses to AMPH.

\section{AMPH augments physiological dopamine signaling}

Physiological dopamine signaling occurs along a temporal spectrum, with slow changes in basal levels mediated by tonic firing of dopamine neurons and presynaptic interactions at one end and the more rapid, transient elevations elicited by burst firing at the other (Schultz, 2007). Our observed effects of AMPH on electrically evoked dopamine responses lead to important predictions for drug action on both modes of neurotransmission in awake, behaving animals. Based on our findings, for example, AMPH should elicit only modest increases in basal extracellular dopamine via DAT reversal because, without vesicular emptying, only the extant, normally low levels of cytosolic dopamine are available for nonexocytotic release. Figure 4, which shows the initial effects of AMPH on nonelectrically evoked recordings, supports this prediction. A slow but small rise in the basal response is observed after administration of high-

dose AMPH (Fig. 4A, left; Fig. 4B). Typically emerging $\sim 90 \mathrm{~s}$ after drug injection and lasting only a few $(<5)$ minutes, this increase above basal dopamine levels was on average $\sim 100 \mathrm{nM}$ and was not observed with low-dose AMPH (Fig. 4C). Statistical analysis demonstrated a significant main effect of drug dose on basal dopamine levels $\left(F_{(2,13)}=30.6, p<0.01\right)$, with AMPH at the high dose of $10 \mathrm{mg} / \mathrm{kg}$ significantly greater than the low dose of $1 \mathrm{mg} / \mathrm{kg}$ and saline $(p<0.05)$.

Another prediction is that with intact vesicular stores, coupled to upregulated exocytotic dopamine release and DAT inhibition, phasic dopamine signaling should not only be functional, but actually augmented by AMPH. Interestingly, although recording sites were optimized in this experiment for robust electrically evoked dopamine levels to assess release and uptake mechanisms and not for spontaneous phasic dopamine release events, whose occurrence is more variable (Wightman et al., 2007), these so-called "dopamine transients" were seen riding on top of the slow-rising envelope induced by high-dose AMPH (Fig. $4 A$, right; Fig. $4 B$ ). This activation of phasic dopamine signaling, which may reflect hedonic aspects of drug action (Stuber 
A
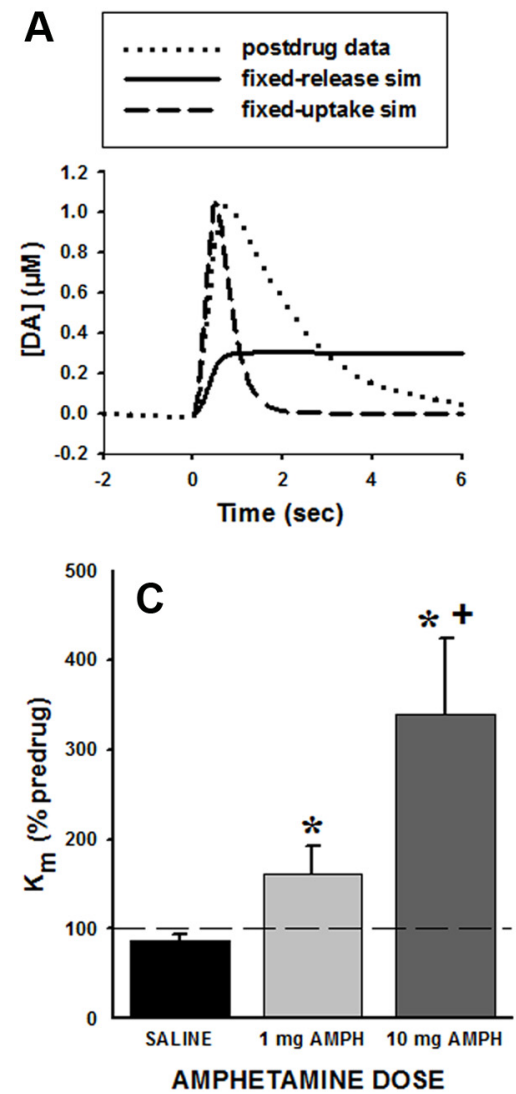


Figure 3. Verification of analysis resolving measures of dopamine release and uptake. Additional analyses were performed to verify that AMPH-induced increases in the electrically evoked dopamine signal measured in awake rats were due to a combination of an upregulation of exocytotic dopamine release and an inhibition of neuronal dopamine uptake. $\boldsymbol{A}$, A sole alteration in either exocytotic dopamine release or neuronal dopamine uptake was not sufficient to capture AMPH effects. Shown are a raw data trace of the evoked dopamine signal collected 10 min post-AMPH (dotted line), with a simulation based on fixing dopamine release at the predrug value and decreasing dopamine uptake to zero (solid line), and with a simulation based on fixing dopamine uptake at the predrug value and increasing dopamine release until the signal maximum matched the postdrug level (dashed line). Even decreasing uptake to zero could not raise the calculated signal amplitude to the observed response. While increasing release did achieve a similar signal amplitude, the rate of uptake in the calculated response was clearly too fast compared with the observed response. $\boldsymbol{B}$, Single-curve analysis demonstrated an upregulation of exocytotic dopamine release for the $10 \mathrm{~min}$ post-AMPH responses in a dose-dependent fashion (saline, $n=5 ; 1 \mathrm{mg} / \mathrm{kg} \mathrm{AMPH}, n=5 ; 10 \mathrm{mg} / \mathrm{kg} \mathrm{AMPH}, n=6$ ). $C, \boldsymbol{D}$, The suitability of using first-order uptake kinetics was tested by analyzing data obtained 10 min post-AMPH injection with Michaelis-Menten uptake kinetics. C, AMPH increased $K_{\mathrm{m}}$ for dopamine uptake in a dose-dependent fashion. $K_{\mathrm{m}}$ is expressed as percentage of the predrug response (\% predrug). $D, A M P H$ increased $[D A]_{p}$, the exocytotic dopamine release term, in a dose-dependent fashion. [DA $]_{p}$ is expressed as percentage of predrug response (\% predrug). Inset, Simulation based on dopamine release and uptake parameters obtained by first-order uptake kinetics ( $\mathrm{k}$ fit) and Michaelis-Menten analysis (MM fit) well described the measured response, demonstrating the veracity of the curve fitting. ${ }^{*} p<0.05$, significantly different from saline; + significantly different from 1 $\mathrm{mg} / \mathrm{kg}$ AMPH. Bars represent the mean $\pm 1 \mathrm{SEM}$.

et al., 2005), suggests that the physiological response to AMPH is complex and could be mediated by action potential-dependent processes in addition to dopamine efflux. We thus quantified spontaneous dopamine transients when baseline recordings were stable. Figure $5 A$ shows an example recording of phasic dopamine signals augmented by high-dose AMPH. In this animal, AMPH increased the duration and amplitude of spontaneous dopamine transients, as predicted by the kinetic analyses of evoked responses. However, we also rather unexpectedly observed a robust increase in their frequency. The time course of dopamine transient activation largely paralleled increases in exocytotic dopamine release and $[\mathrm{DA}]_{\max }$ but was clearly dissociated from the sustained inhibition of dopamine uptake and stereotypy (Fig. 5B-D). Overall, we found that AMPH activated (i.e., $>3 \times$ predrug frequency) these phasic events in animals where spontaneous dopamine transients were observed during predrug recording ( 2 of 5 animals at the $1 \mathrm{mg} / \mathrm{kg}$ dose and 4 of 6 at the $10 \mathrm{mg} / \mathrm{kg}$ dose). AMPH also significantly increased dopamine transient duration (predrug vs postdrug: $217 \pm 17 \mathrm{~ms}$ and $278 \pm 16 \mathrm{~ms}$, respectively) but not amplitude $(3.2 \pm 1.2 \mathrm{~nm}$ and $4.1 \pm 0.4 \mathrm{~nm}$, respectively) at the $1 \mathrm{mg} / \mathrm{kg}$ dose, and both duration $(298 \pm 14 \mathrm{~ms}$ and $564 \pm 12 \mathrm{~ms}$, respectively) and amplitude $(5.0 \pm 0.4 \mathrm{~nm}$ and $22.5 \pm 0.9 \mathrm{~nm}$, respectively) at the 10 $\mathrm{mg} / \mathrm{kg}$ dose ( $t$ test, $p<0.05$ ). In sharp contrast, saline did not alter spontaneous dopamine transients in any of the five animals ( 3 of 5 spontaneously active; duration: $222 \pm 7 \mathrm{~ms}$ and $236 \pm 9 \mathrm{~ms}$, respectively; amplitude: $4.6 \pm 0.4 \mathrm{~nm}$ and $4.1 \pm 0.4 \mathrm{~nm}$, respectively).

\section{Dose-dependent modulation of cue-evoked phasic dopamine signaling} Phasic dopamine release events become time-locked to rewards and their predictive cues during goal-directed learning (Roitman et al., 2004; Day et al., 2007). To determine whether cue-evoked dopamine signals are modulated by AMPH in a manner similar to electrically evoked or spontaneous dopamine transients, we trained rats on a discriminative stimulus (DS) paradigm where distinct audiovisual stimuli signaled the availability of levers that, when pressed, either delivered a sucrose pellet (DS+) or had no programmed consequence (DS-). Recordings in trained rats were made predrug and after injection of saline, $1 \mathrm{mg} / \mathrm{kg} \mathrm{AMPH}$, or $5 \mathrm{mg} / \mathrm{kg}$ AMPH. Rats reliably and selectively responded on DS + trials. Following drug injection, performance varied as a function of AMPH dose. Only injection of $5 \mathrm{mg} / \mathrm{kg}$ altered behavioral performance, abolishing goal-directed behavior (data not shown). Figure 6 shows data acquired during representative recording sessions. Dopamine fluctuations, shown in color, are aligned to presentation of the DS+ (top) and DS- (bottom). Each row corresponds to a single trial and the horizontal white dashed line indicates when injections were made. Representative trials from each recording session are shown below. While the DS + evoked a sharp rise in dopamine concentration predrug in all groups, the DS - failed to evoke any change (compare gray lines above and below). Thus, we went on to statistically analyze AMPH-induced modulation of DS + responses.

Average fluctuations in dopamine concentration were statistically compared for three epochs: from -5 to $0 \mathrm{~s}$ before (baseline), from 0.1 to $2.5 \mathrm{~s}$ after (cue), and from 2.6 to $5 \mathrm{~s}$ after cue onset. Predrug, the DS + evoked a robust and transient increase in dopamine in all groups. A two-way ANOVA revealed a main effect of epoch $\left(F_{(2,34)}=22.8, p<0.01\right)$ but no main effect of group $\left(F_{(2,34)}=0.41, p=0.65\right)$ and no interaction $\left(F_{(4,34)}=0.78\right.$, 
A

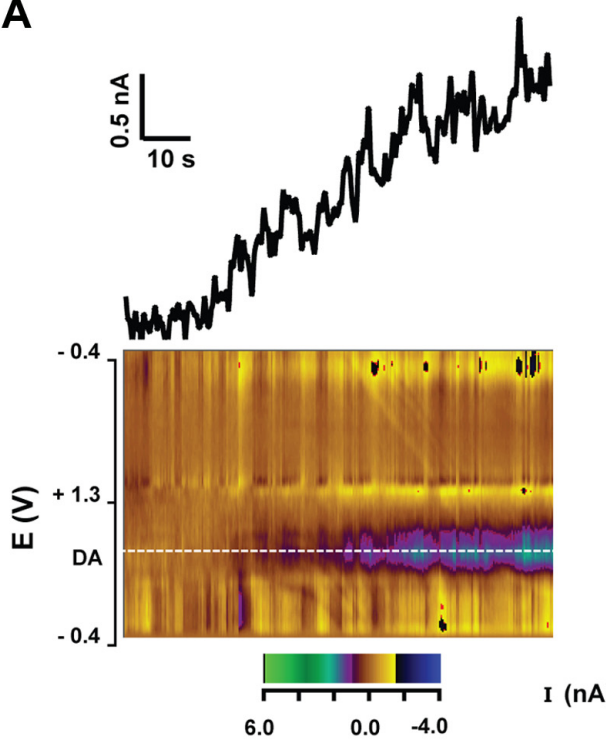

B

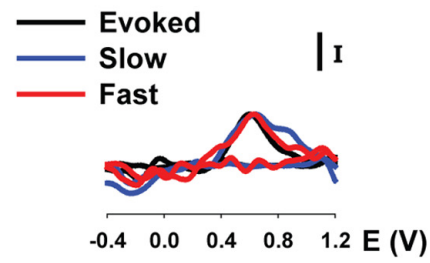

C



Figure 4. AMPH elicits increases in basal dopamine levels. $A$, Background current monitored pre-AMPH and post-AMPH injection provided a relative measure of drug-induced changes in basal extracellular dopamine. Ten milligrams per kilogram AMPH elicited a slow but small (magnitude, $\sim 100 \mathrm{~nm}$ ) and short-lived (duration, $\sim 2$ min) increase in the background current that may reflect, in part, dopamine efflux (left). Faster signals (i.e., phasic dopamine transients) are observed riding on top of this more slowly emerging envelope (right). Pseudocolor plots ( $x$-axis, time; $y$-axis, applied potential; $z$-axis, measured current) show the entire electrochemical profile supporting the identification of dopamine as the origin of both slow and fast signals. $\boldsymbol{B}$, Background-subtracted cyclic voltammograms also identify both slow and fast changes in background signal as dopamine. C, Average amplitude of the slow increases in extracellular dopamine levels (saline, $n=5 ; 1 \mathrm{mg} / \mathrm{kg}$ AMPH, $n=5 ; 10 \mathrm{mg} / \mathrm{kg} \mathrm{AMPH}, n=6)$. ${ }^{*} p<0.05$, significantly different from saline and $1 \mathrm{mg} / \mathrm{kg}$. Bars represent the mean $\pm 1 \mathrm{SE}$.

$p=0.5)$. Thus, data were collapsed into a predrug condition (Fig. $7 A$, Pre-drug). AMPH injection modulated this time-locked response in a dose-dependent manner [significant dose-epoch interaction $\left.\left(F_{(6,72)}=4.0, p<0.01\right)\right]$. This significant interaction was further explored with Tukey's test. Saline injection had no effect on the cue-evoked signal (Fig. $7 B$ ). At a low (1 mg/kg) dose that did not affect behavioral performance, AMPH caused a significantly greater phasic dopamine response to the DS+ relative to predrug (Fig. 7C). However, the DS + failed to elicit a timelocked dopamine signal after administration of $5 \mathrm{mg} / \mathrm{kg}$, a dose that also impaired performance (Fig. 7D).

It is critical to note that, while dopamine transients on average were no longer time-locked to the cue following $5 \mathrm{mg} / \mathrm{kg} \mathrm{AMPH}$, there was a dramatic increase in their overall frequency. That is, phasic events occurred more frequently but randomly throughout the trials (see Fig. 6 for examples). In contrast to the experiment with electrical stimulation, recording sites in animals used for the DS paradigm were optimized for cue-evoked dopamine transients. Under this condition, phasic release events were also spontaneously active during predrug recording in all animals. The number of dopamine transients was thus determined for each $10 \mathrm{~s}$ period before cue onset before and after drug injection. Predrug transient frequency did not differ across groups and was therefore collapsed. Across conditions (predrug, saline, $1 \mathrm{mg} / \mathrm{kg}$ $\mathrm{AMPH}$, and $5 \mathrm{mg} / \mathrm{kg} \mathrm{AMPH}$ ), there was a significant effect of treatment on dopamine transient frequency $\left(F_{(3,34)}=15.9, p<\right.$ 0.01 ), and $5 \mathrm{mg} / \mathrm{kg} \mathrm{AMPH}$ caused a significant increase compared with all other groups $(p<0.05$; Fig. 8$)$.

\section{Discussion}

The accepted model of drug action predicts that AMPH compromises phasic dopamine signaling by the combined actions of vesicular depletion and nonexocytotic efflux. Yet, AMPH enhances behaviors dependent upon intact phasic dopamine signaling. We begin to resolve this paradox by demonstrating in freely behaving rats that AMPH activates dopamine transients. We additionally show that augmented exocytotic dopamine release is a key presynaptic AMPH effect that drives increases in extracellular dopamine and subsequent behavioral changes. This major reassessment of AMPH action contributes to the establishment of a unifying mechanism for abused drugs.

\section{New model of AMPH action}

We found inconsistencies with the accepted view of AMPH action, established in brain slices, as the quintessential dopamine "releaser" (Jones et al., 1998; Schmitz et al., 2001). Our results were obtained using identical microsensor methodology and kinetic analyses but in behaving rats (Garris et al., 2003). Across similar time courses, electrically evoked dopamine responses were enhanced in vivo, rather than compromised as in in vitro studies, by AMPH. The dominant component underlying this potentiation in vivo was upregulated exocytotic dopamine release, which is in sharp contrast to the marked depletion of readily releasable vesicular dopamine stores demonstrated in vitro. Moreover, we observed a 50-fold lower increase in AMPHinduced nonelectrically evoked basal dopamine levels compared with brain slices. Similar to in vitro studies, AMPH caused robust DAT blockade. Thus, while AMPH inhibition of dopamine uptake manifests in vivo as well as in vitro, AMPH disruption of action potential-dependent dopamine neurotransmission is absent in the whole animal.

Discrepancies between AMPH actions in vitro versus in vivo are likely due to a number of factors. For example, reduced capacity for exocytotic dopamine release appears to manifest in vitro (Bowyer et al., 1987; Chen and Ewing, 1995; Floor and Meng, 1996; Anderson et al., 1998; Jones et al., 1998; Schmitz et al., 2001; Mosharov et al., 2003). In contrast, AMPH augmented phasic-like dopamine signals and vesicular dopamine release in anesthetized rats using the same stimulus trains as here in awake rats (Ramsson et al., 2011b). Interestingly, dopamine D2 receptor 
A
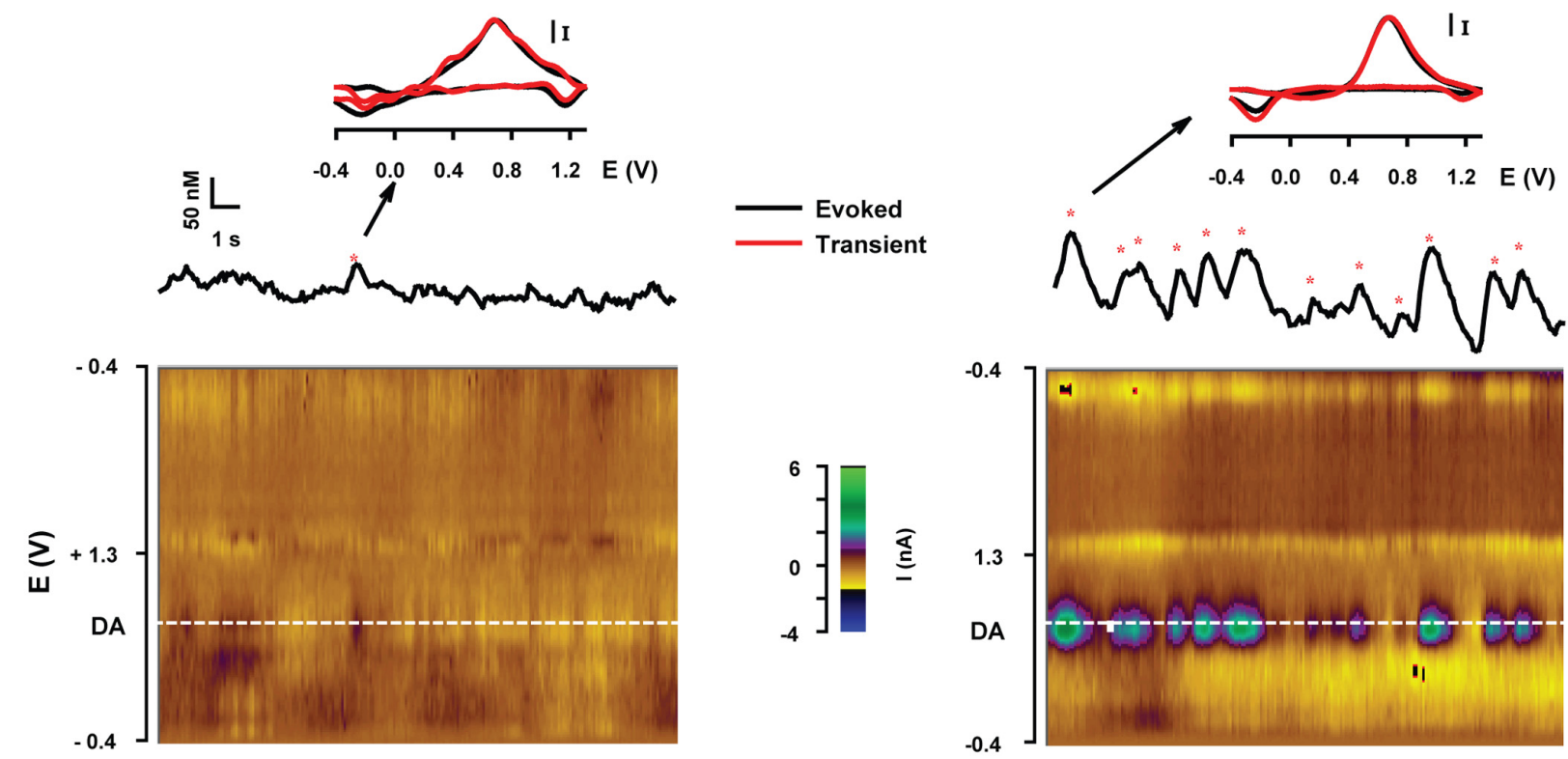

B

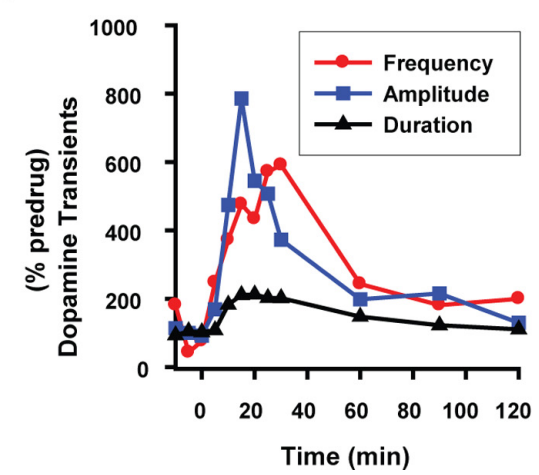

C

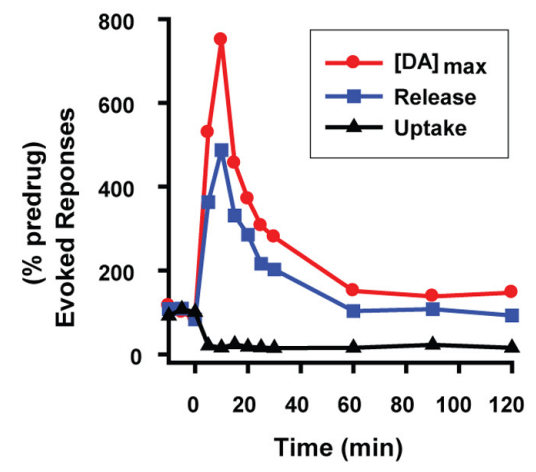

D



Figure 5. AMPH concurrently alters phasic dopamine transients, dopamine release and uptake, and motoric behavior. $\boldsymbol{A}$, AMPH activates phasic dopamine signaling. Red asterisks denote spontaneous phasic transients identified as dopamine and collected predrug (left) or after $10 \mathrm{mg} / \mathrm{kg}$ AMPH (right). Background-subtracted cyclic voltammograms, shown for example transients denoted by the arrow (red line) and for the electrically evoked response (black line), identify dopamine as the signal source. Current is normalized. Pseudocolor plots ( $x$-axis, time; $y$-axis, applied potential; $z$-axis, measured current) demonstrate the entire electrochemical record of transients and their identity as dopamine. $B$, AMPH increased the frequency, amplitude, and duration of dopamine transients. $\boldsymbol{C}$, AMPH increased the magnitude of the evoked dopamine signal $\left([D A]_{\max }\right)$ and exocytotic dopamine release $\left([D A]_{p}\right)$, and inhibited dopamine uptake $(k)$. $\boldsymbol{D}$, AMPH preferentially increased stereotypy over ambulation. All data were collected in a single animal. Data in $\boldsymbol{B}, \boldsymbol{C}$, and $\boldsymbol{D}$ were reported as percentage predrug.

antagonism increases extracellular dopamine levels in the anesthetized rat (Park et al., 2011) to similar micromolar levels observed in vitro (Jones et al., 1998; Schmitz et al., 2001), suggesting that negative feedback mechanisms reign in robust AMPH actions on dopamine release mechanisms in the intact brain. Negative feedback can be minimized in vitro as slice superfusion and cell-synaptosome incubation dilute extracellular dopamine.

Stimulation parameters may also contribute to discrepancies between preparations. Increasing stimulus train duration in vivo switches AMPH effects on electrically evoked dopamine from increasing to decreasing levels (Ewing et al., 1983; Kuhr et al., 1985, 1986; Stamford et al., 1986; May et al., 1988; Suaud-Chagny et al., 1989; Ramsson et al., 2011a). While in vitro studies demonstrating AMPH-induced decreases in vesicular release have used a single stimulus pulse, several micromolar dopamine is elicited (Jones et al., 1998, 1999; Schmitz et al., 2001; Patel et al., 2003; John and Jones, 2007), an order of magnitude greater than the evoked phasic-like dopamine signals recorded here. Thus, AMPH may have different actions on vesicular pools of dopamine and that different stimulations may assess different compo- nents of neurotransmitter storage (Rizzoli and Betz, 2005; Cesca et al., 2010).

To our knowledge, the sustained inhibition of dopamine uptake is the first dopamine correlate documented in vivo to the long-lasting ( $>2 \mathrm{~h}$ ) stereotypy elicited by high-dose AMPH. Because AMPH levels in the brain parallel the shorter-lived increase in dialysate dopamine (Kuczenski et al., 1997) and profiles for exocytotic dopamine release and evoked $[\mathrm{DA}]_{\max }$ shown here, reduced dopamine uptake appears to occur with decreasing brain drug levels and could be mediated by fewer DAT proteins facing outward and/or by DAT internalization (Saunders et al., 2000; Sorkina et al., 2003). Together, our results therefore identify DAT blockade and enhanced exocytotic dopamine release, rather than vesicular depletion or dopamine efflux, as the key presynaptic AMPH actions on dopamine neurons in behaving animals.

\section{AMPH increases basal dopamine levels}

We observed a slow and modest increase in basal dopamine with the high dose of AMPH. This increase could be mediated by 
A
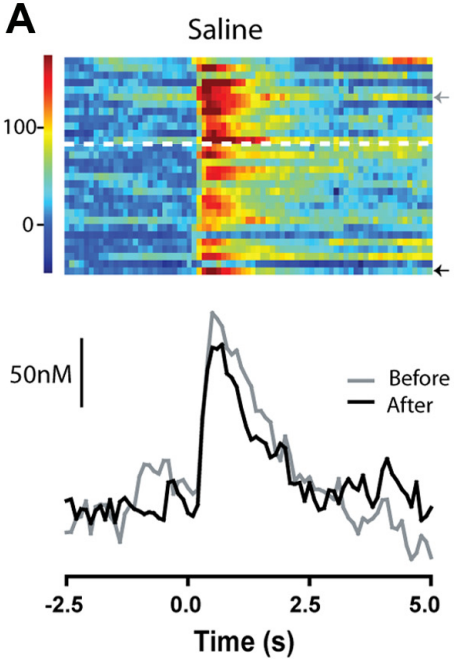

B
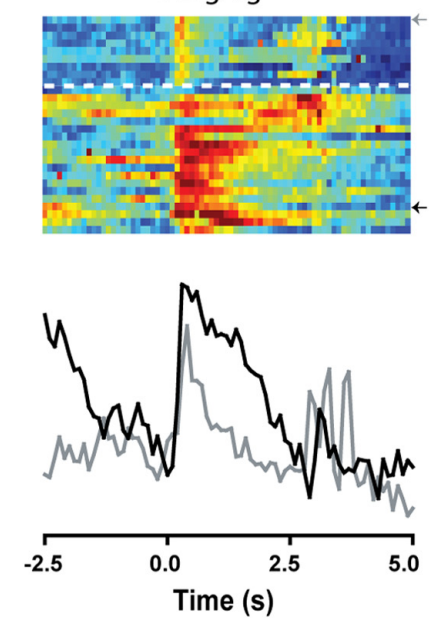

C $\quad 5 \mathrm{mg} / \mathrm{kg}$


D
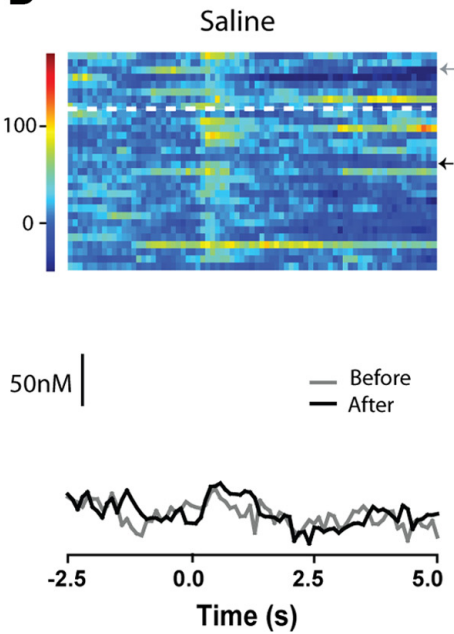

E
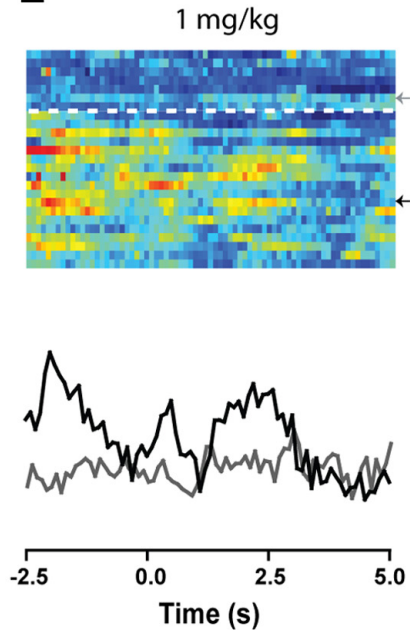

$\mathbf{F}$
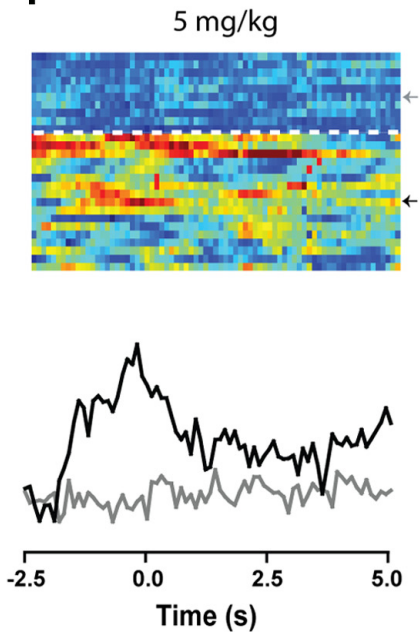

Figure 6. Representative examples of AMPH modulation during the discriminative stimulus task. Each panel represents data from an individual rat. $A-C$, Dopamine responses on DS+ trials. Effects of saline ( $\boldsymbol{A}), 1 \mathrm{mg} / \mathrm{kg} \mathrm{AMPH} \mathrm{(B)}$, and $5 \mathrm{mg} / \mathrm{kg} \mathrm{AMPH} \mathrm{(C)}$. Conventions are the same for all panels. Top, Heat map in which each row represents an individual trial aligned to DS + onset (time 0 ), with dopamine (nм) concentration shown in color in $100 \mathrm{~ms}$ bins. Rows above and below the dashed white line depict trials before and after, respectively, injection. Bottom, Exemplar trials showing dopamine concentration over time taken from the before (gray line) and after injection (black line) phases of the experiment. Gray (before) and black (after) arrows next to the heat map denote the trials illustrated below. $\boldsymbol{D}-\boldsymbol{F}$, Dopamine responses on DS - trials before and after injection of saline $(\boldsymbol{D}), 1 \mathrm{mg} / \mathrm{kg} \mathrm{AMPH}(\boldsymbol{E})$, and $5 \mathrm{mg} / \mathrm{kg}(\boldsymbol{F})$ AMPH. All conventions are as in above.

action potential-dependent and action potential-independent mechanisms. Because dopamine transients, which are action potential-dependent (Sombers et al., 2009), were observed riding on top of the rising envelope, phasic release events could be coalescing. Dopamine neurons also fire tonically to contribute to basal dopamine levels (Schultz, 2007), and AMPH could be activating this component of dopamine signaling combined with enhanced vesicular release and decreased uptake. Finally, AMPH could be eliciting the slow efflux mediated by DAT reversal, which is driven by the cytosolic pool of dopamine (Fleckenstein et al., 2007; Sulzer, 2011). This latter action is independent of phasic dopamine signaling because tetrabenzaine, an inhibitor of the vesicular monoamine transporter, depletes vesicular dopamine stores and induces dopamine efflux while virtually eliminating phasic dopamine transients (Owesson-White et al., 2012). Further study will be required to establish the origin of this modest AMPH-induced increase in basal dopamine levels.

\section{AMPH augments phasic dopamine signaling}

It is possible that phasic dopamine signals occurring under more "natural" conditions are affected by AMPH in a manner more consistent with in vitro studies. In the absence of overt stimuli, dopamine transients occur "spontaneously" (Wightman et al., 2007) and depend on ongoing electrophysiological activity of dopamine neurons (Sombers et al., 2009). Consistent with kinetic analyses performed here, AMPH dose-dependently increased the amplitude and duration of dopamine transients. Surprisingly, AMPH also increased the frequency of these spontaneous phasic events. Thus, it appears that AMPH shares with other drugs of abuse, such as cocaine, nicotine, and ethanol (Cheer et al., 2007; Sombers et al., 2009), the capability to augment phasic dopamine signaling by increasing the frequency of dopamine transients.

AMPH affects goal-directed behavior in a dose-dependent manner. At moderate doses, AMPH potentiates operant re- 

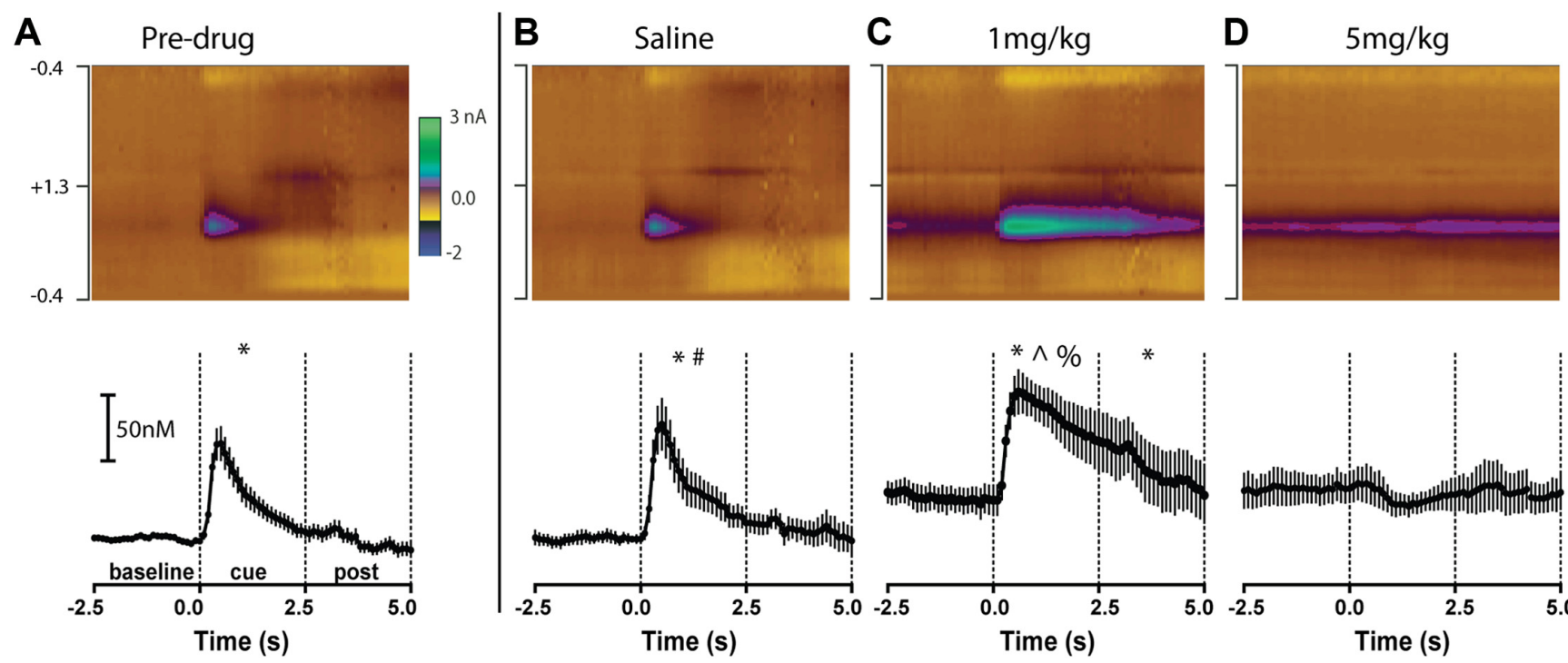

Figure 7. AMPH dose-dependently alters dopamine evoked by a reward predictive cue. Conventions are the same for all panels. A-D, Top, Average pseudocolor plot ( $x$-axis, time; $y$-axis, applied potential; $z$-axis, measured current) shows the entire electrochemical profile supporting the identification of dopamine evoked by the DS + . Bottom, The average dopamine response time-locked to the DS + . Individual points represent mean dopamine and error bars represent \pm 1 SEM. The vertical dashed lines demarcate epochs (baseline, cue, post) used for statistical analyses. Data are shown predrug $(n=20)(\boldsymbol{A})$, and after saline $(n=7)(\boldsymbol{B}), 1 \mathrm{mg} / \mathrm{kg} \mathrm{AMPH}(n=6)(\boldsymbol{C})$, and $5 \mathrm{mg} / \mathrm{kg} \mathrm{AMPH}(n=7)(\boldsymbol{D}) .{ }^{*}$, epochs significantly $(p<0.05)$ different from the baseline epoch before injection. \# indicates that the cue epoch is significantly different from saline baseline. $\wedge$ indicates that the cue epoch is significantly different from $1 \mathrm{mg} / \mathrm{kg}$ baseline. \% indicates that the cue epoch is significantly different from the before injection cue epoch.



Figure 8. AMPH dose-dependently increases the frequency of phasic dopamine transients during the DS paradigm. The number of dopamine transients was determined for each $10 \mathrm{~s}$ period before cue onset before and after drug injection. Before injection, transient frequency did not differ across groups and were therefore collapsed $(n=20)$. Rats were injected with saline $(n=7), 1 \mathrm{mg} / \mathrm{kg}$ AMPH $(n=6)$, or $5 \mathrm{mg} / \mathrm{kg}(n=7) \mathrm{AMPH} .{ }^{*}$, significantly different from all other groups $(p<0.05)$. Bars represent the mean $\pm 1 \mathrm{SE}$.

sponding for food reward (Poncelet et al., 1983; Zhang et al., 2003). Here, a discriminative stimulus paradigm was used to examine the effects of AMPH on operant behavior and phasic dopamine signaling. Similar to previous reports (Roitman et al., 2004; Brown et al., 2011; McCutcheon et al., 2012), a food reward predictive cue evoked a phasic increase in dopamine within milliseconds of cue onset. Low-dose AMPH did not diminish operant responding but increased the magnitude and duration of cue-evoked release, which is consistent with kinetic analyses supporting AMPH-induced increased exocytotic dopamine release and reduced dopamine uptake. In contrast, high-dose AMPH abolished both operant responding and the time-locked phasic dopamine response to the cue. However, dopamine transients were still present and even occurred with higher frequency but randomly throughout the trial. Thus, impaired operant responding at higher doses of AMPH is not due to a loss of phasic dopamine signaling. Instead, the data raise the intriguing possibility that AMPH impairs behavioral performance by disrupting the temporal relationship between behaviorally relevant stimuli and dopamine transients.

While enhanced phasic signaling was not predicted based on the accepted model of AMPH action, some existing evidence supports it. AMPH elicits burst firing in dopamine neurons (Shi et al., 2000; Paladini et al., 2001), which correlates well with the observed increased frequency of spontaneous dopamine transients. Additionally, conductances associated with dopamine transport have been shown to enhance the excitability of dopamine neurons (Ingram et al., 2002). Thus, previous behavioral and electrophysiological studies have established precedence for AMPH-augmented phasic dopamine signaling that counters the postulate of AMPH action by vesicular dopamine depletion and compromised action potential-dependent dopamine neurotransmission.

\section{Clinical significance of the new model of AMPH action}

Demonstrated for cocaine (Venton et al., 2006), methylphenidate (Chadchankar et al., 2012), and other dopamine uptake blockers (Ewing et al., 1983; Lee et al., 2001), the enhancement of exocytotic dopamine release by AMPH may thus be generalized as an important mechanism of psychostimulants. In addition to their well recognized role of inhibiting dopamine uptake (Fleckenstein et al., 2007; Sulzer, 2011), psychostimulant-enhanced exocytotic dopamine release may be an important step in the addiction process. Our results also raise the possibility that enhanced phasic dopamine signaling may underlie important clinical effects of AMPH. Modest activation of dopamine transients at the relatively low dose of $1 \mathrm{mg} / \mathrm{kg}$ used here may be an important action of medications that combine amphetamine salts (e.g., Adderall) used clinically (Joyce et al., 2007). Indeed, low doses of AMPH preserve and improve learning and behavioral performance (Mayorga et al., 2000; Wyvell and Berridge, 2000; Taylor and Jentsch, 2001; Zhang et al., 2003; Knutson et al., 2004). In contrast, high doses of AMPH can produce a behavioral profile 
similar to the positive symptoms associated with schizophrenia (Featherstone et al., 2007; Lisman et al., 2008). Interestingly, schizophrenics are thought to have hyperactive striatal dopamine signaling (Simpson et al., 2010) and fail to detect important stimuli in tests of attention and vigilance (Cornblatt and Keilp, 1994), a result similar to the failure of operant behavior in response to cues after high-dose AMPH shown here. Thus, disrupting the tight temporal concurrence between dopamine transients and important external cues due to hyperactive phasic dopamine signaling may contribute to AMPH-induced psychosis (Featherstone et al., 2007).

\section{References}

Anderson BB, Chen G, Gutman DA, Ewing AG (1998) Dopamine levels of two classes of vesicles are differentially depleted by amphetamine. Brain Res 788:294-301. CrossRef Medline

Bowyer JF, Masserano JM, Weiner N (1987) Inhibitory effects of amphetamine on potassium-stimulated release of $[3 \mathrm{H}]$ dopamine from striatal slices and synaptosomes. J Pharmacol Exp Ther 240:177-186. Medline

Brown HD, McCutcheon JE, Cone JJ, Ragozzino ME, Roitman MF (2011) Primary food reward and reward-predictive stimuli evoke different patterns of phasic dopamine signaling throughout the striatum. Eur J Neurosci 34:1997-2006. CrossRef Medline

Cesca F, Baldelli P, Valtorta F, Benfenati F (2010) The synapsins: key actors of synapse function and plasticity. Prog Neurobiol 91:313-348. CrossRef Medline

Chadchankar H, Ihalainen J, Tanila H, Yavich L (2012) Methylphenidate modifies overflow and presynaptic compartmentalization of dopamine via an alpha-synuclein-dependent mechanism. J Pharmacol Exp Ther 341:484-492. CrossRef Medline

Cheer JF, Wassum KM, Heien ML, Phillips PE, Wightman RM (2004) Cannabinoids enhance subsecond dopamine release in the nucleus accumbens of awake rats. J Neurosci 24:4393-4400. CrossRef Medline

Cheer JF, Heien ML, Garris PA, Carelli RM, Wightman RM (2005) Simultaneous dopamine and single-unit recordings reveal accumbens GABAergic responses: implications for intracranial self-stimulation. Proc Natl Acad Sci U S A 102:19150-19155. CrossRef Medline

Cheer JF, Wassum KM, Sombers LA, Heien ML, Ariansen JL, Aragona BJ, Phillips PE, Wightman RM (2007) Phasic dopamine release evoked by abused substances requires cannabinoid receptor activation. J Neurosci 27:791-795. CrossRef Medline

Chen G, Ewing AG (1995) Multiple classes of catecholamine vesicles observed during exocytosis from the Planorbis cell body. Brain Res 701:167174. CrossRef Medline

Cornblatt BA, Keilp JG (1994) Impaired attention, genetics, and the pathophysiology of schizophrenia. Schizophr Bull 20:31-46. CrossRef Medline

Day JJ, Roitman MF, Wightman RM, Carelli RM (2007) Associative learning mediates dynamic shifts in dopamine signaling in the nucleus accumbens. Nat Neurosci 10:1020-1028. CrossRef Medline

Ebner SR, Roitman MF, Potter DN, Rachlin AB, Chartoff EH (2010) Depressive-like effects of the kappa opioid receptor agonist salvinorin A are associated with decreased phasic dopamine release in the nucleus accumbens. Psychopharmacology (Berl) 210:241-252. CrossRef Medline

Ewing AG, Bigelow JC, Wightman RM (1983) Direct in vivo monitoring of dopamine released from two striatal compartments in the rat. Science 221:169-171. CrossRef Medline

Featherstone RE, Kapur S, Fletcher PJ (2007) The amphetamine-induced sensitized state as a model of schizophrenia. Prog Neuropsychopharmacol Biol Psychiatry 31:1556-1571. CrossRef Medline

Fleckenstein AE, Volz TJ, Riddle EL, Gibb JW, Hanson GR (2007) New insights into the mechanism of action of amphetamines. Annu Rev Pharmacol Toxicol 47:681-698. CrossRef Medline

Floor E, Meng L (1996) Amphetamine releases dopamine from synaptic vesicles by dual mechanisms. Neurosci Lett 215:53-56. CrossRef Medline

Garris PA, Budygin EA, Phillips PE, Venton BJ, Robinson DL, Bergstrom BP, Rebec GV, Wightman RM (2003) A role for presynaptic mechanisms in the actions of nomifensine and haloperidol. Neuroscience 118:819-829. CrossRef Medline

Heien ML, Johnson MA, Wightman RM (2004) Resolving neurotransmitters detected by fast-scan cyclic voltammetry. Anal Chem 76:5697-5704. CrossRef Medline
Hyman SE, Malenka RC, Nestler EJ (2006) Neural mechanisms of addiction: the role of reward-related learning and memory. Annu Rev Neurosci 29:565-598. CrossRef Medline

Ingram SL, Prasad BM, Amara SG (2002) Dopamine transporter-mediated conductances increase excitability of midbrain dopamine neurons. Nat Neurosci 5:971-978. CrossRef Medline

John CE, Jones SR (2007) Voltammetric characterization of the effect of monoamine uptake inhibitors and releasers on dopamine and serotonin uptake in mouse caudate-putamen and substantia nigra slices. Neuropharmacology 52:1596-1605. CrossRef Medline

Jones JL, Day JJ, Aragona BJ, Wheeler RA, Wightman RM, Carelli RM (2010) Basolateral amygdala modulates terminal dopamine release in the nucleus accumbens and conditioned responding. Biol Psychiatry 67:737-744. CrossRef Medline

Jones SR, Gainetdinov RR, Wightman RM, Caron MG (1998) Mechanisms of amphetamine action revealed in mice lacking the dopamine transporter. J Neurosci 18:1979-1986. Medline

Jones SR, Joseph JD, Barak LS, Caron MG, Wightman RM (1999) Dopamine neuronal transport kinetics and effects of amphetamine. J Neurochem 73:2406-2414. Medline

Joyce BM, Glaser PE, Gerhardt GA (2007) Adderall produces increased striatal dopamine release and a prolonged time course compared to amphetamine isomers. Psychopharmacology (Berl) 191:669-677. CrossRef Medline

Knutson B, Bjork JM, Fong GW, Hommer D, Mattay VS, Weinberger DR (2004) Amphetamine modulates human incentive processing. Neuron 43:261-269. CrossRef Medline

Kuczenski R, Segal DS, Aizenstein ML (1991) Amphetamine, cocaine, and fencamfamine: relationship between locomotor and stereotypy response profiles and caudate and accumbens dopamine dynamics. J Neurosci 11: 2703-2712. Medline

Kuczenski R, Melega WP, Cho AK, Segal DS (1997) Extracellular dopamine and amphetamine after systemic amphetamine administration: comparison to the behavioral response. J Pharmacol Exp Ther 282:591-596. Medline

Kuhr WG, Ewing AG, Near JA, Wightman RM (1985) Amphetamine attenuates the stimulated release of dopamine in vivo. J Pharmacol Exp Ther 232:388-394. Medline

Kuhr WG, Bigelow JC, Wightman RM (1986) In vivo comparison of the regulation of releasable dopamine in the caudate nucleus and the nucleus accumbens of the rat brain. J Neurosci 6:974-982. Medline

Lee TH, Balu R, Davidson C, Ellinwood EH (2001) Differential time-course profiles of dopamine release and uptake changes induced by three dopamine uptake inhibitors. Synapse 41:301-310. CrossRef Medline

Lisman JE, Coyle JT, Green RW, Javitt DC, Benes FM, Heckers S, Grace AA (2008) Circuit-based framework for understanding neurotransmitter and risk gene interactions in schizophrenia. Trends Neurosci 31:234-242. CrossRef Medline

Logman MJ, Budygin EA, Gainetdinov RR, Wightman RM (2000) Quantitation of in vivo measurements with carbon fiber microelectrodes. J Neurosci Methods 95:95-102. CrossRef Medline

Lüscher C, Ungless MA (2006) The mechanistic classification of addictive drugs. PLoS Med 3:e437. CrossRef Medline

May LJ, Kuhr WG, Wightman RM (1988) Differentiation of dopamine overflow and uptake processes in the extracellular fluid of the rat caudate nucleus with fast-scan in vivo voltammetry. J Neurochem 51:1060-1069. CrossRef Medline

Mayorga AJ, Popke EJ, Fogle CM, Paule MG (2000) Similar effects of amphetamine and methylphenidate on the performance of complex operant tasks in rats. Behav Brain Res 109:59-68. CrossRef Medline

McCutcheon JE, Beeler JA, Roitman MF (2012) Sucrose-predictive cues evoke greater phasic dopamine release than saccharin-predictive cues. Synapse 66:346-351. CrossRef Medline

Mosharov EV, Gong LW, Khanna B, Sulzer D, Lindau M (2003) Intracellular patch electrochemistry: regulation of cytosolic catecholamines in chromaffin cells. J Neurosci 23:5835-5845. Medline

Owesson-White CA, Roitman MF, Sombers LA, Belle AM, Keithley RB, Peele JL, Carelli RM, Wightman RM (2012) Sources contributing to the average extracellular concentration of dopamine in the nucleus accumbens. J Neurochem 121:252-262. CrossRef Medline

Paladini CA, Fiorillo CD, Morikawa H, Williams JT (2001) Amphetamine 
selectively blocks inhibitory glutamate transmission in dopamine neurons. Nat Neurosci 4:275-281. CrossRef Medline

Park J, Takmakov P, Wightman RM (2011) In vivo comparison of norepinephrine and dopamine release in rat brain by simultaneous measurements with fast-scan cyclic voltammetry. J Neurochem 119:932-944. CrossRef Medline

Patel J, Mooslehner KA, Chan PM, Emson PC, Stamford JA (2003) Presynaptic control of striatal dopamine neurotransmission in adult vesicular monoamine transporter 2 (VMAT2) mutant mice. J Neurochem 85:898910. CrossRef Medline

Paxinos G, Watson C (1986) The rat brain in stereotaxic coordinates, 2nd edition. New York: Academic.

Poncelet M, Chermat R, Soubrie P, Simon P (1983) The progressive ratio schedule as a model for studying the psychomotor stimulant activity of drugs in the rat. Psychopharmacology (Berl) 80:184-189. CrossRef Medline

Ramsson ES, Covey DP, Daberkow DP, Litherland MT, Juliano SA, Garris PA (2011a) Amphetamine augments action potential-dependent dopaminergic signaling in the striatum in vivo. J Neurochem 117:937-948. CrossRef Medline

Ramsson ES, Howard CD, Covey DP, Garris PA (2011b) High doses of amphetamine augment, rather than disrupt, exocytotic dopamine release in the dorsal and ventral striatum of the anesthetized rat. J Neurochem 119:1162-1172. CrossRef Medline

Richfield EK, Penney JB, Young AB (1989) Anatomical and affinity state comparisons between dopamine $\mathrm{D} 1$ and $\mathrm{D} 2$ receptors in the rat central nervous system. Neuroscience 30:767-777. CrossRef Medline

Rizzoli SO, Betz WJ (2005) Synaptic vesicle pools. Nat Rev Neurosci 6:5769. CrossRef Medline

Roitman MF, Stuber GD, Phillips PE, Wightman RM, Carelli RM (2004) Dopamine operates as a subsecond modulator of food seeking. J Neurosci 24:1265-1271. CrossRef Medline

Roitman MF, Wheeler RA, Wightman RM, Carelli RM (2008) Real-time chemical responses in the nucleus accumbens differentiate rewarding and aversive stimuli. Nat Neurosci 11:1376-1377. CrossRef Medline

Saunders C, Ferrer JV, Shi L, Chen J, Merrill G, Lamb ME, Leeb-Lundberg LM, Carvelli L, Javitch JA, Galli A (2000) Amphetamine-induced loss of human dopamine transporter activity: an internalization-dependent and cocaine-sensitive mechanism. Proc Natl Acad Sci U S A 97:6850-6855. CrossRef Medline

Schmitz Y, Lee CJ, Schmauss C, Gonon F, Sulzer D (2001) Amphetamine distorts stimulation-dependent dopamine overflow: effects on D2 autoreceptors, transporters, and synaptic vesicle stores. J Neurosci 21: 5916-5924. Medline

Schultz W (2007) Behavioral dopamine signals. Trends Neurosci 30: 203-210. CrossRef Medline

Shi WX, Pun CL, Zhang XX, Jones MD, Bunney BS (2000) Dual effects of D-amphetamine on dopamine neurons mediated by dopamine and nondopamine receptors. J Neurosci 20:3504-3511. Medline

Simpson EH, Kellendonk C, Kandel E (2010) A possible role for the striatum in the pathogenesis of the cognitive symptoms of schizophrenia. Neuron 65:585-596. CrossRef Medline

Sinkala E, McCutcheon JE, Schuck MJ, Schmidt E, Roitman MF, Eddington DT (2012) Electrode calibration with a microfluidic flow cell for fastscan cyclic voltammetry. Lab Chip 12:2403-2408. CrossRef Medline
Sombers LA, Beyene M, Carelli RM, Wightman RM (2009) Synaptic overflow of dopamine in the nucleus accumbens arises from neuronal activity in the ventral tegmental area. J Neurosci 29:1735-1742. CrossRef Medline

Sorkina T, Doolen S, Galperin E, Zahniser NR, Sorkin A (2003) Oligomerization of dopamine transporters visualized in living cells by fluorescence resonance energy transfer microscopy. J Biol Chem 278:28274-28283. CrossRef Medline

Stamford JA, Kruk ZL, Millar J (1986) Measurement of stimulated dopamine release in the rat by in vivo voltammetry: the influence of stimulus duration on drug responses. Neurosci Lett 69:70-73. CrossRef Medline

Stuber GD, Wightman RM, Carelli RM (2005) Extinction of cocaine selfadministration reveals functionally and temporally distinct dopaminergic signals in the nucleus accumbens. Neuron 46:661-669. CrossRef Medline

Suaud-Chagny MF, Buda M, Gonon FG (1989) Pharmacology of electrically evoked dopamine release studied in the rat olfactory tubercle by in vivo electrochemistry. Eur J Pharmacol 164:273-283. CrossRef Medline

Sulzer D (2011) How addictive drugs disrupt presynaptic dopamine neurotransmission. Neuron 69:628-649. CrossRef Medline

Taylor JR, Jentsch JD (2001) Repeated intermittent administration of psychomotor stimulant drugs alters the acquisition of Pavlovian approach behavior in rats: differential effects of cocaine, $d$-amphetamine and 3,4- methylenedioxymethamphetamine ("ecstasy"). Biol Psychiatry 50:137-143. CrossRef Medline

Tsai HC, Zhang F, Adamantidis A, Stuber GD, Bonci A, de Lecea L, Deisseroth $\mathrm{K}$ (2009) Phasic firing in dopaminergic neurons is sufficient for behavioral conditioning. Science 324:1080-1084. CrossRef Medline

Venton BJ, Seipel AT, Phillips PE, Wetsel WC, Gitler D, Greengard P, Augustine GJ, Wightman RM (2006) Cocaine increases dopamine release by mobilization of a synapsin-dependent reserve pool. J Neurosci 26:3206-3209. CrossRef Medline

Wightman RM, Heien ML, Wassum KM, Sombers LA, Aragona BJ, Khan AS, Ariansen JL, Cheer JF, Phillips PE, Carelli RM (2007) Dopamine release is heterogeneous within microenvironments of the rat nucleus accumbens. Eur J Neurosci 26:2046-2054. CrossRef Medline

Willuhn I, Wanat MJ, Clark JJ, Phillips PE (2010) Dopamine signaling in the nucleus accumbens of animals self-administering drugs of abuse. Curr Top Behav Neurosci 3:29-71. CrossRef Medline

Wu Q, Reith ME, Wightman RM, Kawagoe KT, Garris PA (2001) Determination of release and uptake parameters from electrically evoked dopamine dynamics measured by real-time voltammetry. J Neurosci Methods 112:119-133. CrossRef Medline

Wyvell CL, Berridge KC (2000) Intra-accumbens amphetamine increases the conditioned incentive salience of sucrose reward: enhancement of reward "wanting" without enhanced "liking" or response reinforcement. J Neurosci 20:8122-8130. Medline

Zhang M, Balmadrid C, Kelley AE (2003) Nucleus accumbens opioid, GABaergic, and dopaminergic modulation of palatable food motivation: contrasting effects revealed by a progressive ratio study in the rat. Behav Neurosci 117:202-211. CrossRef Medline

Zweifel LS, Parker JG, Lobb CJ, Rainwater A, Wall VZ, Fadok JP, Darvas M, Kim MJ, Mizumori SJ, Paladini CA, Phillips PE, Palmiter RD (2009) Disruption of NMDAR-dependent burst firing by dopamine neurons provides selective assessment of phasic dopamine-dependent behavior. Proc Natl Acad Sci U S A 106:7281-7288. CrossRef Medline 